\title{
MERCURY-INDUCED NEUROBEHAVIORAL DEFICIT AND ITS AMELIORATING EFFECTS OF AQUEOUS EXTRACT OF TRAPA BISPINOSA
}

\author{
PANKAJ PHUKAN ${ }^{1}$, SANJIT NAMASUDRA ${ }^{1}$, MEENAKSHI BAWARI $^{1 *}$, MAHUYA SENGUPTA $^{2}$ \\ ${ }^{1}$ Department of Life Science and Bioinformatics, Assam University, Silchar - 788 011, Assam, India. ${ }^{2}$ Department of Biotechnology, Assam \\ University, Silchar - 788 011, Assam, India.Email: mbawari.aus@gmail.com
}

Received: 12 June 2018, Revised and Accepted: 19 July 2018

\section{ABSTRACT}

Objective: The aim of this study was to evaluate the effects of aqueous extract of dry fruits of Trapa bispinosa (TB) in alleviating mercury (Hg)-induced neurobehavioral toxicity.

Methods: A total of 36 adult male Swiss albino mice weighing 25-30 g were equally divided into six groups, namely I-VI. Group I received distilled water, Group II received mercuric chloride (1.5 mg/kg), Group III received TB extract low dose (150 mg/kg), Group IV received TB extract high dose (300 mg/kg), Group V received mercuric chloride plus TB extract low dose, and Group VI received mercuric chloride plus TB extract high dose. All the groups received doses orally through oral gavage tube and the treatment lasted for 14 days. The behavioral effects were evaluated with locomotor activity in the open field test (OFT), spatial learning ability and memory in the Morris water maze test (MWM), immobility in Forced swimming test (FST) and anxiety in Elevated plus maze test (EPM).

Result: In the present study, it was observed that Hg-exposed mice significantly decreased the locomotor activity (p<0.001), time spent in open arms $(\mathrm{p}<0.001)$, number of open arm entries $(\mathrm{p}<0.01)$, number of annulus crossovers $(\mathrm{p}<0.001)$ and increased immobility $(\mathrm{p}<0.001)$, escape latency $(\mathrm{p}<0.01)$, and path length $(\mathrm{p}<0.001)$ in mice. The aqueous extract of TB significantly reduced the neurotoxic effects of Hg. The aqueous extract of TB showed to increase the locomotor activity $(\mathrm{p}<0.01)$, time spent in open arms $(\mathrm{p}<0.01)$, number of open arm entries $(\mathrm{p}<0.05)$, and number of annulus crossovers $(\mathrm{p}<0.001)$, which was decreased in Hg-exposed mice. TB extract also showed to decrease the immobility ( $<<0.001)$, escape latency $(\mathrm{p}<0.05)$, and path length $(\mathrm{p}<0.001)$ in Hg-fed mice.

Conclusion: On the basis of the results obtained from the behavioral study, the present study indicates that mercuric chloride caused neurobehavioral changes which were significantly reversed by the aqueous extract of TB. Thus, TB was found to be effective in ameliorating the neurobehavioral deficit induced by $\mathrm{Hg}$ exposure.

Keywords: Neurotoxicity, Neuroprotection, Herbal medicine, Mercury, Heavy metal, Neuroprotective plant, Behavior.

(c) 2018 The Authors. Published by Innovare Academic Sciences Pvt Ltd. This is an open access article under the CC BY license (http://creativecommons. org/licenses/by/4. 0/) DOI: http://dx.doi.org/10.22159/ajpcr.2018.v11i9.27908

\section{INTRODUCTION}

Mercury (Hg) is one of the most dangerous environmental pollutants [1]. It is a highly neurotoxic compound leading to neurological and developmental deficits in animals and man [2]. Although Hg-induced neurotoxicity is an extensively reported phenomenon, there are no effective treatments available which completely abolish its toxic effects [3]. Since ancient times, herbs are being used in treating various kinds of diseases. Medicinal herbs constitute the cornerstone of traditional medicinal practice worldwide. These medicinal plants represent a great deal of untapped reservoir of drugs and the structural diversity of their component molecule makes a valuable source of novel lead compounds [4]. Conventionally, Trapa bispinosa (TB) has been used in India for several important medicinal purposes. The fruits of TB are used as intestinal astringent, aphrodisiac, and anti-inflammatory, and in leprosy, urinary discharges, fractures, sore throat, bronchitis, and anemia [5]. TB fruit is claimed nervine tonic and useful in nervous debility [6]. Taking into account, the absence of effective treatments for Hg poisoning and the medicinal properties of TB, this study aims to evaluate the effects of fruits of TB in alleviating Hg-induced neurotoxicity.

\section{METHODS}

Plants materials

The plant material TB (fruits of TB) was collected from Dibrugarh district of Assam, India, and was identified and authenticated by Botanical Survey of India, Shillong as T. natans var. bispinosa (Roxb.) Makino (Number-BSI/ERC/2015/Plant identification/668).

\section{Animals}

Adult male Swiss albino mice weighing between 20 and $30 \mathrm{~g}$ used for the study were obtained from the Pasture Institute, Shillong. The animals were housed in cages under standard environmental conditions and had free access to food and water ad libitum. The experiments were performed in accordance with the guidelines in the care and use of laboratory animals and were approved by the Ethical Committee of the Assam University, Silchar.

\section{$\mathrm{Hg}$}

Mercuric chloride was obtained from Hi-Media.

\section{Preparation of extract}

The plant materials (fruits of TB) were shade dried under room temperature for about 45 days. The shade-dried fruits were powdered and the extract was prepared using Soxhlet extractor, and after extraction, the sample was filtered with no. 1 Whatman filter paper and then the filtrate was evaporated to dryness at $40^{\circ} \mathrm{C}$. The dried extract was weighed and dissolved in distilled water to give the required concentration before administration to the experimental animals.

\section{Preliminary phytochemical screening}

The extract was screened for the presence of various phytochemical constituents, namely alkaloids, carbohydrates, flavonoids, saponin, proteins, amino acid, oils, and fats [7-12]. 


\section{Dose selection}

The dosage of the extract was determined after toxicity test (LD50) median lethal dose described by Lorke [13]. The $150 \mathrm{mg} / \mathrm{kg}$ b.wt and $300 \mathrm{mg} / \mathrm{kg}$ b.wt were taken as the low dose and high dose, respectively.

\section{Experimental design}

All the animals were randomly divided into six groups, each containing six mice. The groups of mice were treated as follows: (i) Control (distilled water); (ii) mercuric chloride $(1.5 \mathrm{mg} / \mathrm{kg}$ ); (iii) fruit extract low dose $(150 \mathrm{mg} / \mathrm{kg}) ;$ (iv) fruit extract high dose $(300 \mathrm{mg} / \mathrm{kg})$; (v) mercuric chloride + fruit extract low dose; and (vi) mercuric chloride + fruit extract high dose. All administrations were performed orally to the respective group up to a volume of $2 \mathrm{ml} / 100 \mathrm{~g}$ body weight for 14 days. The experiments were performed $1 \mathrm{~h}$ after the administration of the last dose.

\section{Open field test (OFT)}

The locomotor activity was assessed using the open field apparatus after Pardon et al. (2000) with slight modifications. The apparatus, made of wood, had a floor of $50 \mathrm{~cm} \times 50 \mathrm{~cm}$ divided by black lines into 25 squares of $10 \mathrm{~cm} \times 10 \mathrm{~cm}$. The walls were of $25 \mathrm{~cm}$ in height. The test room was illuminated at the same intensity as the colony room. Each mouse was placed in the center of the open field, and its behavior was observed for $5 \mathrm{~min}$. The parameter evaluated was the total number of squares crossed. At the end of each test, the whole area was cleaned with a wet sponge and a dry paper towel. Doses were administered orally $60 \mathrm{~min}$ before the test session [14].

\section{Forced swimming test (FST)}

The FST was used for the evaluation of antidepressant activity in mice. The FST was performed according to the procedure described by Porsolt with slight modifications. Briefly, the animals were individually forced to swim in a transparent glass vessel (25 cm high, $15 \mathrm{~cm}$ in diameter) filled with $\left(12.5 \mathrm{~cm}\right.$ high) water at $23 \pm 1^{\circ} \mathrm{C}$. The duration of immobility (in second) was measured for $5 \mathrm{~min}$. After the test, mice were removed from the glass vessel and then dried and placed in their home cage. "Immobility" was defined as floating and treading water just enough to keep the nose above water. The immobility reflected a state of lowered mood in which the animals had given up hope of finding an exit and had resigned themselves to the experimental situation. The water was changed after every other trial [15]

\section{Elevated plus maze test (EPM)}

The EPM is an animal model where the behavioral repertoire of rodents is used to detect effects on anxiety. The test is based on the natural aversion of mice for open and elevated areas, as well as on their natural spontaneous exploratory behavior in novel environments. Locally fabricated wooden EPM apparatus consisting of two open arms $(30 \mathrm{~cm} \times 8 \mathrm{~cm})$ and two enclosed arms $(30 \mathrm{~cm} \times 8 \mathrm{~cm} \times 15 \mathrm{~cm})$ having an open roof was used. The maze was elevated to the height of $40 \mathrm{~cm}$ from the floor in a dimly lit room. Mice were placed individually at the center of the EPM facing an enclosed arm and allowed to explore the maze for $5 \mathrm{~min}$. The time spent by the mouse on the open and enclosed arm and the center and also the number of entries in open arms were recorded. Arm entries were defined as entry of all four paws into an arm. The apparatus was thoroughly cleaned after removal of the mice. Increased exploratory activity in the open arm was taken as an indication of anxiolytic activity [16].

\section{Morris water maze test (MWM)}

The apparatus used for MWM was a circular swimming pool of $110 \mathrm{~cm}$ diameter and $30 \mathrm{~cm}$ high, filled to a depth of $15 \mathrm{~cm}$ with water maintained at $23 \pm 1^{\circ} \mathrm{C}$. The water maze test was performed as described by Vorhees and Williams, 2006. Briefly, the mice were trained for 5 consecutive days, followed by the probe trial on day 6 . The mice were let down in four random places (N, S, E, and W) in the pool. The order of these was changed daily in a random manner. The mice were trained 4 times per day $(60 \mathrm{~s} /$ trial). Animals not finding the platform within this time limit were either placed on the platform or guided to it. After the $60 \mathrm{~s}$ swim, they were allowed to stay on the platform for $15 \mathrm{~s}$ before the next swim trial. Single probe trials to test reference memory were conducted 1 day after the last training session. Mice were released at a random start position and were allowed to swim for $30 \mathrm{~s}$ in the absence of the platform. In this test, escape latency, i.e.,the time taken to find the hidden platform and path length, i.e., the distance traveled by the mice to find the hidden platform and number of annulus crossovers were measured. The tracks were recorded using a video camera and Animal Tracker software [17]. The latencies and path length of training days 1-5 were compared with the average latency and path length for each day. For the analysis of the probe tests, the number of target annulus crossovers was compared [18].

\section{Statistical analysis}

The data were analyzed using SPSS. Statistical significance of difference was evaluated using one-way analysis of variance followed by Tukey's procedure for multiple comparisons. The data were expressed as mean \pm standard error of mean. $p<0.05$ was considered statistically significant.

\section{RESULTS}

\section{Preliminary phytochemical screening}

Results obtained in this experiment showed the presence of alkaloids, flavonoids, saponin, carbohydrates, and phenolic compounds (Table 1).

\section{OFT}

The locomotor activity in the OFT during the 5 min duration is shown in Fig. 1. In the animals of Group II treated with mercuric chloride, the number of squares crossed was decreased significantly as compared with the Group I, i.e., controls ( $\mathrm{p}<0.001)$. However, a significant increase in the number of squares crossed was observed in Group I $(\mathrm{p}<0.001)$, Group III ( $\mathrm{p}<0.01)$, Group IV ( $\mathrm{p}<0.01)$, Group V ( $<<0.005)$, and Group VI $(\mathrm{p}<0.01)$ as compared to Group II.

\section{FST}

The results of the FST are reported in Fig. 2. In animals of Group II treated with mercuric chloride, the immobility time was increased significantly as compared with the Group I, i.e., controls $(\mathrm{p}<0.001)$. However, a significant decrease in the immobility time was observed in Group I ( $\mathrm{p}<0.001)$, Group III ( $<<0.001)$, Group IV ( $<<0.001)$, Group V $(\mathrm{p}<0.001)$, and Group VI $(\mathrm{p}<0.001)$ as compared to Group II.

\section{EPM}

The results of the EPM are reported in Figs. 3 and 4. In animals of Group II treated with mercuric chloride, the time spent in the open arms $(p<0.001)$ and the number of entries into the open arms $(p<0.01)$ were significantly decreased as compared with the Group I, i.e. control. However, a significant increase in the time spent in the open arms was observed in Group I ( $\mathrm{p}<0.001)$, Group III $(\mathrm{p}<0.001)$, Group IV $(\mathrm{p}<0.001)$, Group V $(\mathrm{p}<0.05)$, and Group VI $(\mathrm{p}<0.01)$ as compared to Group II, and a significant increase in the number of entries in the open arms was found in Group I ( $p<0.01)$, Group III $(p<0.01)$, Group IV ( $p<0.01)$, and Group VI $(\mathrm{P}<0.05)$ as compared to Group II. The time spent in the closed

Table 1: Phytochemical screening of aqueous extract of Trapa bispinosa

\begin{tabular}{lll}
\hline Alkaloids & Mayer's test & +ve \\
& Wagner's test & + ve \\
Carbohydrates & Fehling's test & + ve \\
& Benedict's test & + ve \\
Phenolic compounds & Ferric chloride test & + ve \\
& Alkaline reagent test & + ve \\
Saponin & Kokate, 1999 & + +ve \\
Proteins/amino acids & Biuret test & -ve \\
& Ninhydrin test & -ve \\
Oils/fats & Spot test & -ve \\
& Saponification test & -ve \\
Glycosides & Borntrager's test & -ve \\
\hline
\end{tabular}

-ve: Absence, +ve: Presence 
arms was also observed to increase in Group I $(\mathrm{p}<0.001)$, Group III $(\mathrm{p}<0.001)$, Group IV $(\mathrm{p}<0.001)$, Group V $(\mathrm{p}<0.01)$, and Group VI $(\mathrm{p}<0.001)$ as compared to Group II.

\section{MWM test}

In the $2^{\text {nd }}$ day of training in MWM, in Group II treated with mercuric chloride, the escape latency was increased significantly as compared with the Group I, i.e. controls $(\mathrm{p}<0.05)$. In the $3^{\text {rd }}$ day, $4^{\text {th }}$ day, and $5^{\text {th }}$ day, the escape latency was decreased significantly in Group I, Group III, Group IV, Group V, and Group VI as compared to Group II (Figs. 5 and 6).

In the $3^{\text {rd }}$ day of training in MWM, in Group II treated with mercuric chloride, the path length was increased significantly as compared with the Group I, i.e., controls $(\mathrm{p}<0.05)$. In the $4^{\text {th }}$ day, the path length was decreased significantly in Group I $(\mathrm{p}<0.01)$, Group III $(\mathrm{p}<0.001)$, Group IV ( $\mathrm{p}<0.001)$, and Group VI $(\mathrm{p}<0.05)$ as compared to Group II.

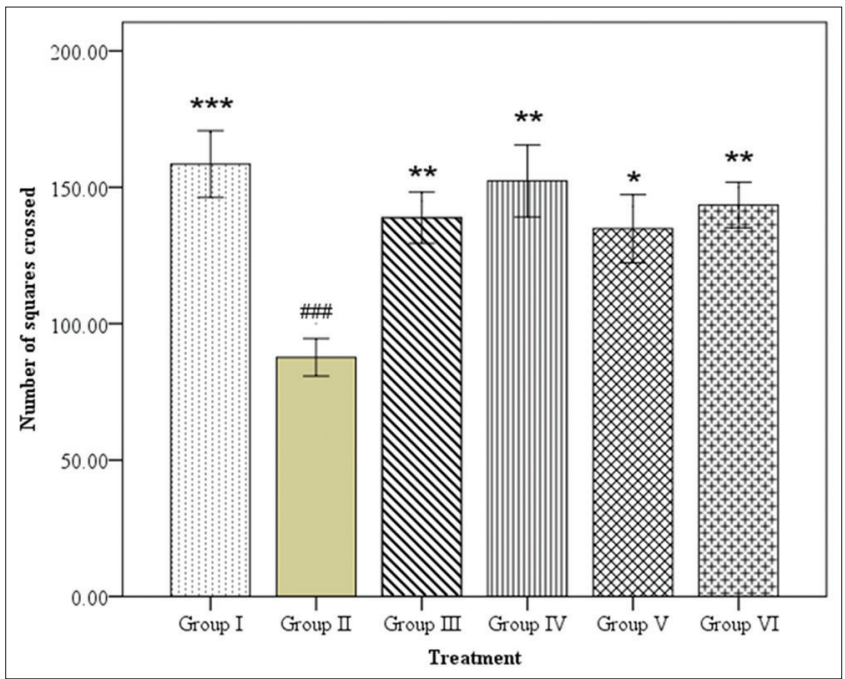

Fig. 1: Locomotor activity in open field test. Each column represents mean \pm standard error of mean $(n=6)$. Comparisons were made using one-way analysis of variance followed by Turkey's multiple comparison test $\left({ }^{*} \mathbf{p}<0.05 ;{ }^{* *} p<0.01\right.$ $* * * \mathbf{p}<0.001$ vs. Group II and \#p<0.05; \#\#p<0.01; \#\#\#P<0.001 vs. Group I)

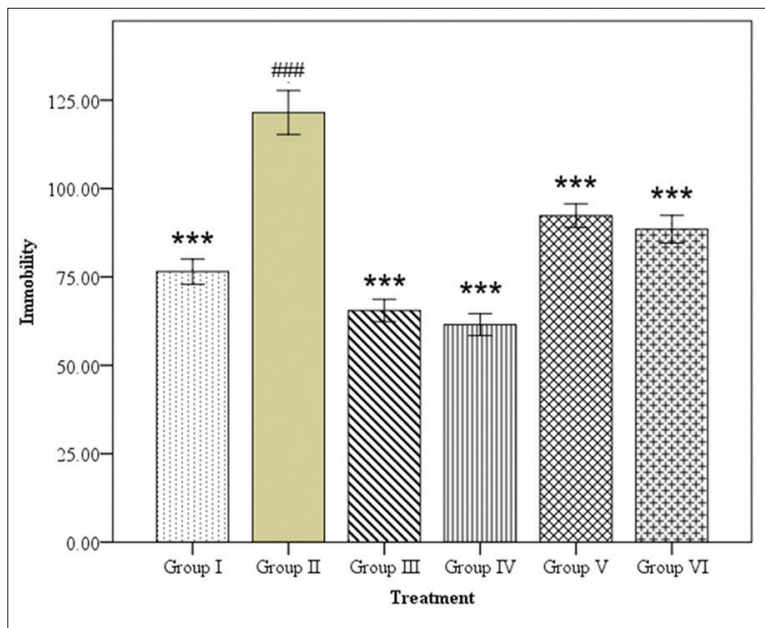

Fig. 2: Immobility in forced swimming test. Each column represents mean \pm standard error of mean $(n=6)$. Comparisons were made using one-way analysis of variance followed by Turkey's multiple comparison test $\left({ }^{*} p<0.05 ; * * p<0.01\right.$ ${ }^{* * *} \mathbf{p}<0.001$ vs. Group II and \#p<0.05; \#\#p<0.01; \#\#\#p<0.001 vs. Group I)
In the $5^{\text {th }}$ day, the path length was decreased significantly in Group I ( $p<0.001)$, Group III $(p<0.001)$, Group IV ( $<<0.001)$, Group V ( $p<0.001)$, and Group VI ( $\mathrm{p}<0.001)$ as compared to Group II (Fig. 7).

In the animals of Group II treated with mercuric chloride, the annulus crossed was decreased significantly as compared with the Group I, i.e., controls $(p<0.001)$. However, a significant increase in the annulus crossed was observed in Group I $(\mathrm{p}<0.001)$, Group III $(\mathrm{p}<0.001)$, Group IV ( $\mathrm{p}<0.001)$, Group V $(\mathrm{p}<0.001)$, and Group VI $(\mathrm{p}<0.001)$ as compared to Group II (Fig. 8).

\section{DISCUSSION}

An important step in evaluating the action of a substance on the central nervous system (CNS) is to observe its effect on the behavior of the animal. In the present study, the effects of aqueous extract of TB on

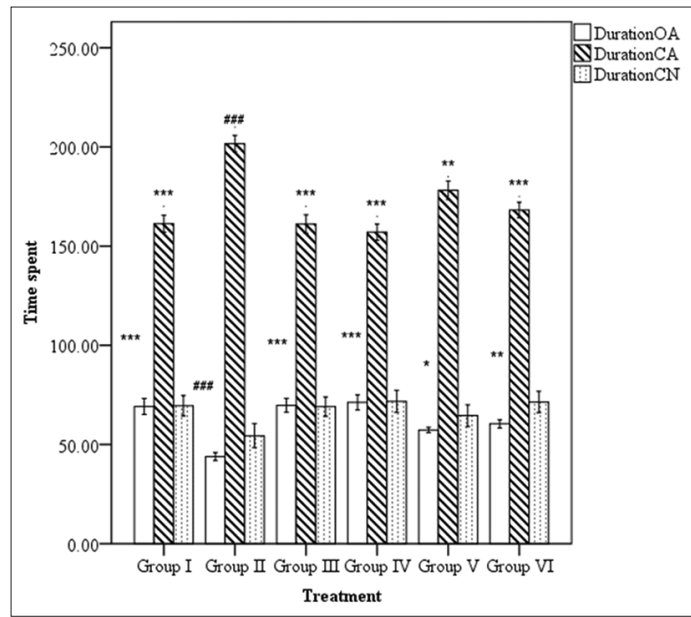

Fig. 3: Time spent in open (duration $\mathrm{OA}$ ) and closed arms (duration CA) and in the center (duration $\mathrm{CN}$ ) in elevated plus maze. Each column represents mean \pm standard error of mean

$(n=6)$. Comparisons were made using one-way analysis of variance followed by Turkey's multiple comparison test $(* \mathrm{p}<0.05$; ${ }^{* *} \mathbf{p}<0.01$; ${ }^{* * *} \mathrm{P}<0.001$ vs. Group II and \#p $<0.05$; \#\#p $<0.01$; \#\#\#p<0.001 vs. Group I)

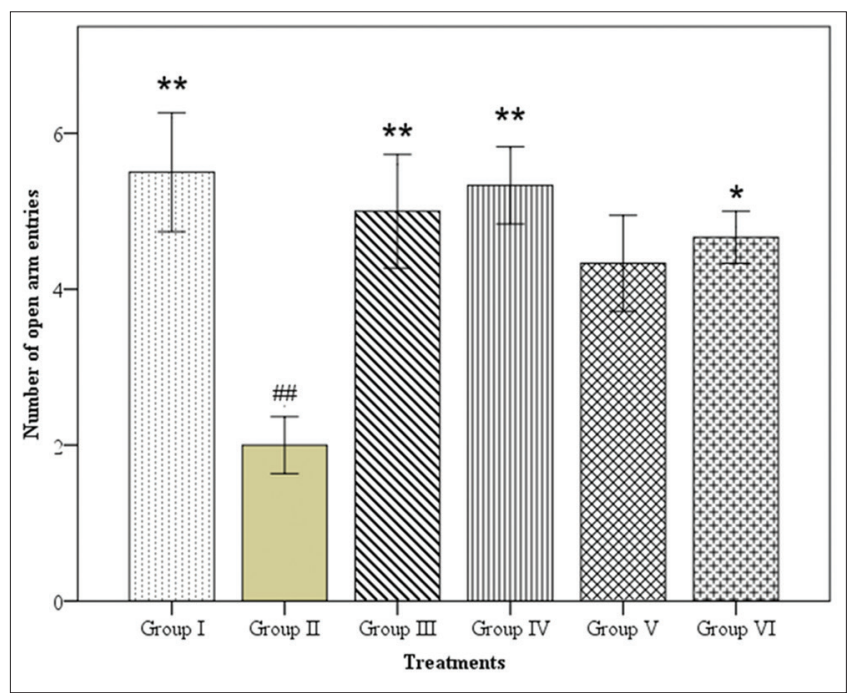

Fig. 4: Number of entries into open arms in elevated plus maze. Each column represents mean \pm standard error of mean $(n=6)$. Comparisons were made using one-way analysis of variance followed by Turkey's multiple comparison test $\left({ }^{*} \mathrm{p}<0.05 ;{ }^{* *} \mathrm{p}<0.01 ;{ }^{* * *} \mathrm{p}<0.001\right.$ vs. Group II and \#p<0.05; \#\#p<0.01; \#\#\#p<0.001 vs. Group I) 
certain neurobehavioral paradigms changes have been evaluated. For this study, two doses of aqueous extract of TB were selected to note the effects of the different doses on the behavior of the Hg-fed mice. The study revealed that the different doses produced different significant level in most of the neurobehavioral tests performed in this study, thereby inferring that dose may play an important role in the efficacy of the extract.

The OFT is one of the most widely used platforms in animal behavioral studies. A number of important conventional and ethological parameters can be collected and analyzed during the performance of the OFT. These data allow measuring behaviors ranging from overall locomotor activity to anxiety-related emotional behaviors [14]. In the present study, the OFT was used to assess locomotor activity in mice. The result indicated that mercuric chloride significantly decreased locomotor activity as compared to control group which shows that it has CNS depressant activity. The decrease in locomotion implies depression effect on CNS. It also gives an indication of the level of excitability of the CNS, and the decrease may be closely related to sedation resulting from depression of the CNS. The group cotreated with mercuric chloride and plant extract showed a significant increase in locomotor activity as compared to mercuric chloride-treated group. The high dose of plant extract was found to be more effective in enhancing the locomotion of $\mathrm{Hg}$-fed mice at a significant level of 0.01 than the low dose of the extract (0.05).

The forced swim test is a rodent behavioral test used for the evaluation of antidepressant drugs, antidepressant efficacy of new compounds, and experimental manipulations that are aimed at rendering or preventing depressive-like states [19]. In FST, mice are forced to swim in an inescapable situation and they tend to become immobile after initial vigorous activity. This immobility reflects a state of lowered mood in which the animals have given up hope of finding an exit and has resigned themselves to the experimental situation [20]. This immobility has been described as a symptom of behavioral despair and has been suggested as an animal model of human depression. The significant increase in immobility time in the mercuric chloride-treated animals as compared to the control animals indicates depressant activity of mercuric chloride, which is opposite to the effect of Group V and VI which received both mercuric chloride and the extract indicating antidepressant activity of the aqueous extract of TB. In forced swim test, both the high and low doses were equally effective in reducing immobility of mice at a significant level of 0.001 .

The exposure of mice to an EPM induces an exploratory cum fear drive which results in anxiety. Anxiolytic compounds by decreasing anxiety, increase the open arm exploration as well as the number of entries into the open arm [21]. In the present study, mercuric chloride-treated group showed to decrease the time spent in open arms and also number of entries into open arms. Whereas the group cotreated with mercuric chloride and plant extract showed to reverse the effects of mercuric chloride-treated group. Thus, we can infer that the plant at the doses studied possess anxiolytic activity. The high dose of the plant extract was found to increase the time spent in open arms and also number of entries in open arms significantly more than the low dose of plant extract. Hence, the high dose is more effective in reducing anxiety than the low dose of the extract.

The MWM is a widely used test in studies of learning and memory with rodents. The MWM is a test of spatial learning for rodents that rely on distal cues to navigate from start locations around the perimeter of an open swimming arena to locate a submerged escape platform [22]. Spatial learning is assessed across repeated trials and reference memory is determined by preference for the platform area when the platform is absent. As shown in Fig. 6, training of mice for 5 days in MWM leads to progressive improvement of acquisition, the ability of mice to explore the hidden platform in the target quadrant. The decline in latency time indicates that mice got trained with the task given on the maze [18]. This is further evident by the decrease in path length (Fig. 7). Exposure to mercuric chloride resulted in significant increase
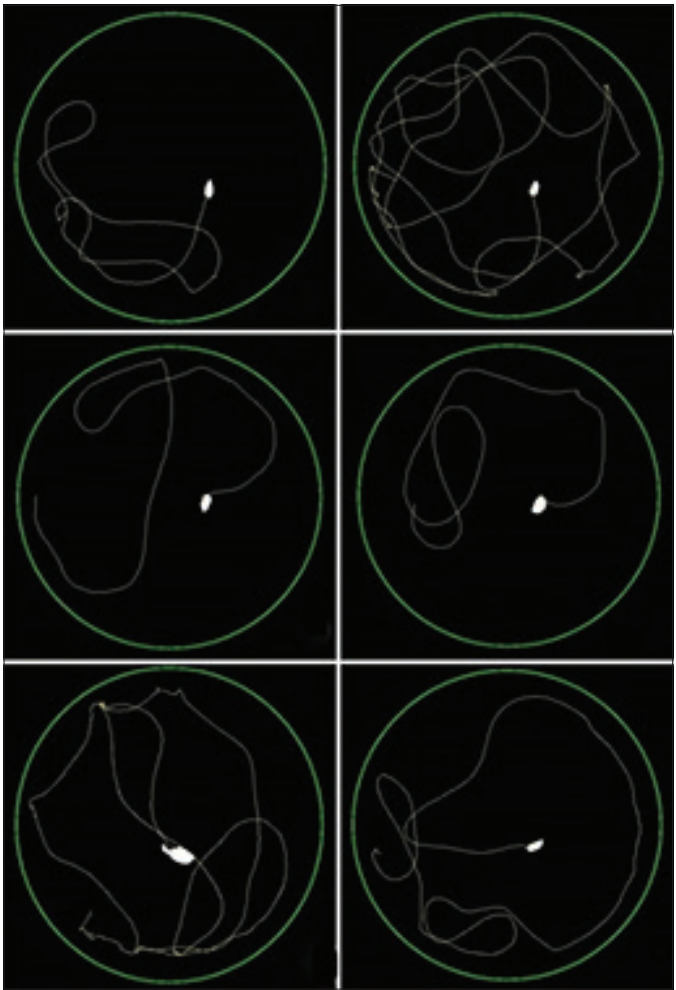

Fig. 5: Representative images of tracking of mice behavior in Morris water maze test. (a) Group I, (b) Group II, (c) Group III, (d) Group IV, (e) Group V, (f) Group VI

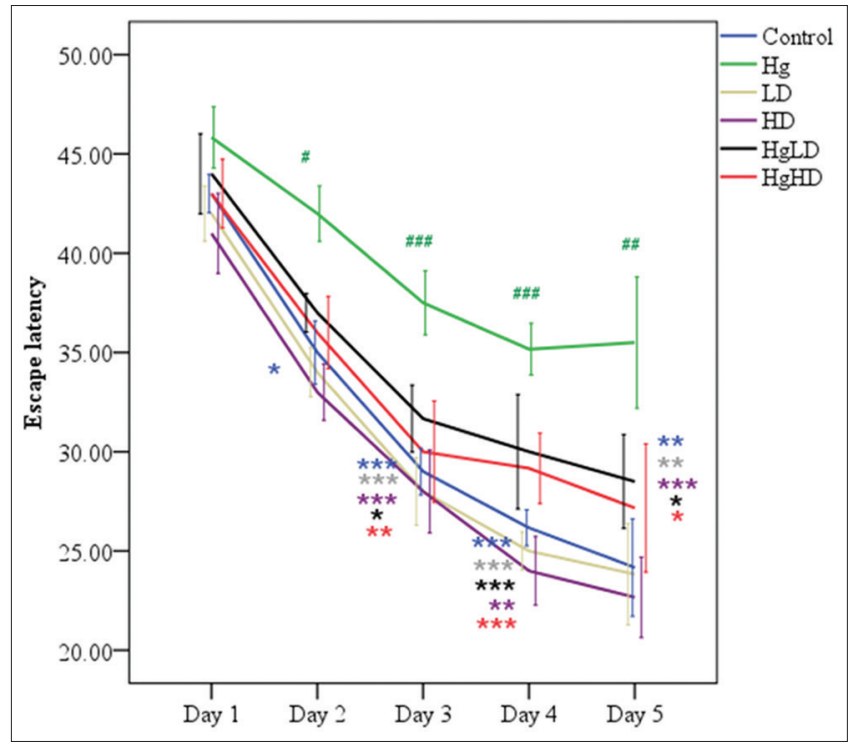

Fig. 6: Escape latency in Morris water maze. The data are represented as mean \pm standard error of mean $(n=6)$.

Comparisons were made using one-way analysis of variance followed by Turkey's multiple comparison test $\left({ }^{*} \mathrm{p}<0.05\right.$; ${ }^{* *} \mathbf{p}<0.01 ; * * * \mathbf{p}<0.001$ vs. Group II and \#p<0.05; \#\#p<0.01; \#\#\#p<0.001 vs. Group I; Group I=Control; Group II=Hg; Group III=LD; Group IV=HD; Group V=HgLD; Group VI=HgHD)

in the latency $(\mathrm{p}<0.01)$ and path length $(\mathrm{p}<0.001)$ as compared to the control group. The mice administered with TB and mercuric chloride, i.e. in Group IV and V showed significant decrease in the latency and path length as compared to mercuric chloride-treated group, the high dose of plant extract was significantly more effective in reducing path 
length than that of low dose. In the probe trial test, in which the hidden platform was removed, mice exposed to mercuric chloride showed significant decrease $(\mathrm{p}<0.001)$ in number of platform crossings (Fig. 8) as compared to the control group. Conversely, in the Group III, IV, V, and VI mice which were given the treatment of TB showed a significant increase $(p<0.001)$ in the number of platform crossings as compared to mercuric chloride groups, here both the high and low doses were equally effective in increasing the number of platform crossed at a significant level of 0.001 . Thus, this indicates that the TB possesses the ability to enhance spatial learning and memory.

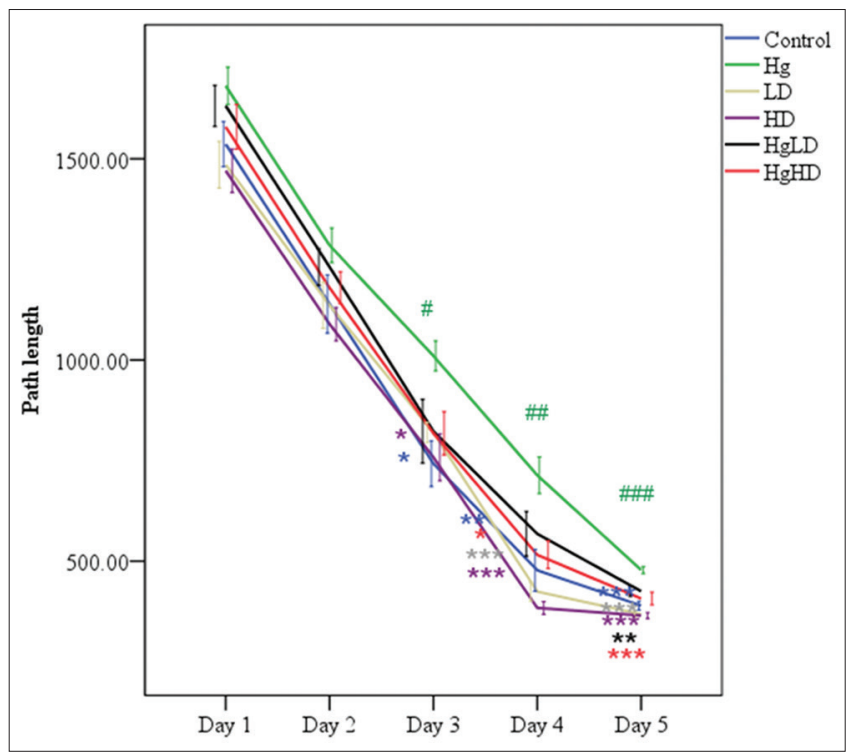

Fig. 7: Path length in Morris water maze. The data are represented as mean \pm standard error of mean $(n=6)$. Comparisons were made using one-way analysis of variance followed by Turkey's multiple comparison test $\left({ }^{*} \mathbf{p}<0.05 ;{ }^{* *} \mathbf{p}<0.01 ;{ }^{* * *} \mathbf{p}<0.001\right.$ vs. Group II and $\# \mathbf{p}<0.05 ; \# \# \mathbf{p}<0.01 ; \# \# \# \mathbf{p}<0.001$ vs. Group I; Group I=Control; Group II=Hg; Group III=LD; Group IV=HD; Group V=HgLD; Group $\mathrm{VI}=\mathrm{HgHD}$ )

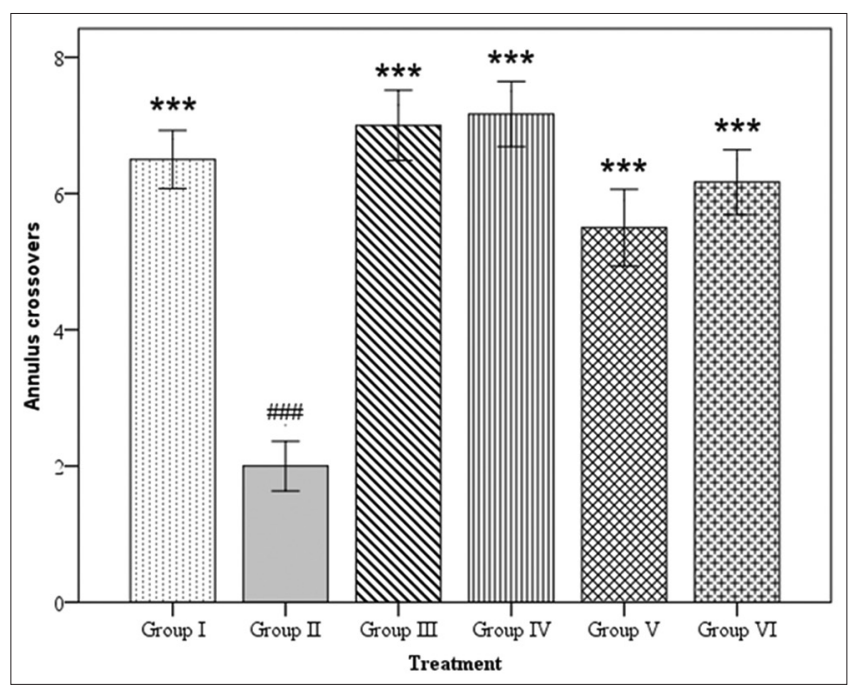

Fig. 8: Number of annulus crossed in Morris water maze. Each column represents mean \pm standard error of mean $(n=6)$. Comparisons were made using one-way analysis of variance followed by Turkey's multiple comparison test $\left({ }^{*} p<0.05\right.$; ${ }^{* *} \mathbf{p}<0.01 ; * * * \mathbf{p}<0.001$ vs. Group II and \#p<0.05; \#\#p<0.01; \#\#\#p<0.001 vs. Group I)

\section{CONCLUSION}

On the basis of the results obtained from the behavioral study of the extract and mercuric chloride, the present study indicates that mercuric chloride caused neurobehavioral changes which were significantly reversed by the aqueous extract of TB and the high dose of the extract was more effective than the low dose. The behavioral study also indicated the extract to possess neuroprotective potential with antidepressant and anxiolytic activities and to improve learning and spatial memory in mice. However, further study is necessary to understand the mechanism of neuroprotection of the plant extract against mercuric chloride and the phytochemical constituents responsible for it.

\section{AUTHOR'S CONTRIBUTIONS}

All the authors contributed equally.

\section{CONFLICTS OF INTEREST}

The authors declare that there are no conflicts of interest regarding the publication of this paper.

\section{REFERENCES}

1. Sabarathinam J, Vishnu PV, Gayathri R. Mercury poisoning and management: A systematic review. Asian J Pharm Clin Res 2016;9:8-12.

2. Bernhoft RA. Mercury toxicity and treatment: A review of the literature. J Environ Public Health 2012;2012:460508.

3. do Nascimento JL, Oliveira KR, Crespo-Lopez ME, Macchi BM, Maués LA, Pinheiro Mda C, et al. Methylmercury neurotoxicity \& amp; antioxidant defenses. Indian J Med Res 2008;128:373-82.

4. Pooja S, Vidyasagar GM. Ethnomedicinal plants used by Rajgond Tribes of Haladkeri village in Bidar District, Karnataka, India. Int J Pharm Pharm Sci 2015;7:216-20

5. Jain SK, Parihar S, Pandey N. Medicinal plants with neuropharmacological properties from Indian origin. Int $\mathrm{J}$ Pharm Pharm Sci 2014;6:36-40.

6. Phukan P, Bawari M, Sengupta M. Promising neuroprotective plants from North-East India. Int J Pharm Pharm Sci 2015;7:28-39.

7. Kokate CK. Practical Pharmacognosy. $4^{\text {th }}$ ed. Madras: Vallabh Prakashan; 1999

8. Evans WC. Trease and Evans Pharmacognosy. $4^{\text {th }}$ ed. Singapore: Harcourt Brace and Company, Asia Pvt Ltd.; 1997.

9. Siddiqui AA, Ali M. Practical Pharmaceutical Chemistry. $1^{\text {st }}$ ed. New Delhi: CBS Publishers and Distributors; 1997.

10. Harborne JB. Phytochemical Methods. London: Chapman and Hall Ltd; 1973.

11. Fisher DB. Protein staining of ribboned epon sections for light microscopy. Histochemie 1968;16:92-6.

12. Sofowora A. Medicinal Plants and Traditional Medicine in Africa. $2^{\text {nd }}$ ed. Nigeria: Spectrum Books; 1993.

13. Lorke D. A new approach to practical acute toxicity testing. Arch Toxicol 1983;54:275-87.

14. Pardon M, Pérez-Diaz F, Joubert C, Cohen-Salmon C. Age-dependent effects of a chronic ultramild stress procedure on open-field behaviour in B6D2F1 female mice. Physiol Behav 2000;70:7-13.

15. Porsolt RD, Le Pichon M, Jalfre M. Depression: A new animal model sensitive to antidepressant treatments. Nature 1977;266:730-2

16. Lister RG. The use of a plus-maze to measure anxiety in the mouse. Psychopharmacology (Berl) 1987;92:180-5.

17. Gulyás M, Bencsik N, Pusztai S, Liliom H, Schlett K. AnimalTracker: An imageJ-based tracking API to create a customized behaviour analyser program. Neuroinformatics 2016;14:479-81.

18. Vorhees CV, Williams MT. Morris water maze: Procedures for assessing spatial and related forms of learning and memory. Nat Protoc 2006;1:848-58.

19. Petit-Demouliere B, Chenu F, Bourin M. Forced swimming test in mice: A review of antidepressant activity. Psychopharmacology (Berl) 2005; 177:245-55.

20. Porsolt RD, Bertin A, Blavet N, Deniel M, Jalfre M. Immobility induced by forced swimming in rats: Effects of agents which modify central catecholamine and serotonin activity. Eur J Pharmacol 1979;57:201-10.

21. Fernández Espejo E. Structure of the mouse behaviour on the elevated plus-maze test of anxiety. Behav Brain Res 1997;86:105-12.

22. Morris R. Developments of a water-maze procedure for studying spatial learning in the rat. J Neurosci Methods 1984;11:47-60. 